Mavi Atlas, 5(2)/2017: 289-301. Araştırma Makalesi | Research Article

Makale Geliş | Received: 01.07.2017

Makale Kabul | Accepted: 26.07.2017

DOI: 10.18795/gumusmaviatlas.337245

Çetin BALANUYE

Doç. Dr. | Assoc. Prof. Dr. Akdeniz Üniversitesi, Edebiyat Fakültesi, Felsefe Bölümü, Antalya-Türkiye Akdeniz University, Faculty of Letters, Department of Philosophy, Antalya-Turkey orcid.org/0000-0002-2601-5476 balanuye@akdeniz.edu.tr

\title{
Yeni Gerçekçiliğin Kant Gerilimi
}

$\ddot{O} \mathbf{z}$

Özellikle son yirmi yılda, dünyanın farklı bölgelerinden görece genç bir grup filozof Kant felsefesinin bazı unsurlarına karşı bir itiraz dillendirmeye başladı. Kendilerine yeni gerçekçilik teması altında farklı adlar veren bu filozoflar, her ne kadar Kant'in yerine ne konacağ Kanţ̧ı epistemolojinin belli bazı vurgularına karşı tam bir fikir birliğinde gibi görünmekteler. Felsefe ve felsefi ontolojide "gerçekçi" bir perspektifi benimsediklerini vurgulayan bu isimler, gerçekliğin spekülatif de olsa yaratıcı bazı araştırma yaklaşımları yoluyla anlaşılabileceğini, bu araştırmada insan merkezciliğin (anthropocentrism) hiçbir türüne yaklaşmamak kaydıyla ve buna karşın, gerçekliğe üst seviyede bir bağlılı̆̆ın olanaklı olduğunu göstermeyi amaçladıklarını vurgulamaktalar. Bu gerçekçi ontoloji araştırmasının taraflarına göre vaat ettikleri gerçekçilik ancak Kantçı epistemoloji ve onun kısıtlayıcı kabullerini aşmakla olanaklıdır. Bu çalışmada, sözü edilen yeni gerçekçi ontoloji arayışlarının çözümlemesi ve Kantçı epistemolojiyle girştikleri tartışmanın irdelenmesi amaçlanmaktadır.

Anahtar Kelimeler: Gerçekçilik, Obje, Ontoloji, Epistemoloji, Spekülasyon.

\section{The Kantian Tension of New Realism}

\begin{abstract}
Particularly in the last two decades a group of young philosophers from different parts of the world have initiated an objection against Kant. Though these philosophers are not always in complete aggrement with each other with regard to what they put instead of Kant, they are almost in full aggreement in their arguments against Kantian epistemology. These young philosophers call themselves as "realists" and like to develop a new realist ontology which is going to be away from anthropocentrism of any kind, yet remaining faitfull to the reality as mcuh as possible. According to these philosophers Kantian epistemology is the one that they have to overcome if they are to achieve this quite a challenging task. This piece of work aims to introduce this new debate and answer in what sense these emerging realist movement needs to break up with Kantian epistemology.
\end{abstract}

Keywords: Realism, Object, Ontology, Epistemology, Speculation. 


\section{Geriplan}

Kant sonrası felsefe, önünde temel bir sorun buldu: Ontoloji ile epistemoloji ya Kant'1n öngördüğü gibi iç içe geçecek ve ilki ikincisine mahkum olacaktı ya da felsefe her iki kalkışmadan da etik bir tevazu tavrıyla geri çekilecekti. Her iki yolu deneyenler de oldu. İki yolun sonunda felsefenin buluştuğu yer bir çeşit 'muallak olanla yetinme'ye dönüştü. 20. yüzyılın ikinci yarısında bu yetinmenin adına “post-modernizm” denildi.

Kant sonrası felsefede ilk yolu deneyenler sahiden de Kant'ın bizi bıraktığı yerden fazla uzaklaşamadı: Aşkınsal (transcendental) olanağın kozmostaki yegane sahibi insan-özne, başka tüm varlıklardan farklı olarak, yalnızca yönelmiyor, düşünmüyor ya da kavramıyor; ama yönelişini, düşünüşünü ya da kavrayışını olanaklı kılan koşulları da fark edebiliyordu. Kant'ın meşhur a priori formları ve kategorileri, insanın bir şeyi ancak zamansallık, mekansallık ya da nedensellik dolayımıyla anlayabileceğini söylediğinde ontoloji hızla epistemolojinin içinde eritilmiş oldu. Kendi içinde şey’i bilemeyeceğini bilmek, şeylerin çeşitlendirdiği kozmosta ancak insani $a$ priori dolayımlardan ibaret bir alanda felsefe yapılabileceğini de kabul etmek anlamına geldi. İkinci yolu deneyenler ise Kant'ın bizi bıraktığı yerde, ne gerçekliğin nesnel olarak var olduğunu ne de -varsa bile- bu tür bir gerçekliğin bilinebilir olduğunu düşündü. Nesnel gerçekliği keşfetmeye yönelik ontolojik araştırmalar ve hipotezler, böylece peşine düşülmesi gereksiz boş bir çaba gibi görünmenin yanısıra, savaşların, çevre felaketlerinin, hayal kırıklı̆̆ı olmuş dev kurtuluş ümitlerinin, insanın insana eziyetinin de sorumlusu sayıldi. ${ }^{1}$

Bu geri planın bir ürünü olan post-modernizm (yanısıra, yeni pragmatizm, sosyal inşacılık, epistemolojik görecelik vb.) özellikle dilsel dönüş denen dönemle birlikte, gerçekliğin hepten kurulan, üstelik dil-içinde ve dil-aracılığıyla kurulan, epistemolojik açıdan da tarihe, kültüre ve dile bağlı olarak her seferinde yeniden kurulacak bir şey

\footnotetext{
${ }^{1}$ Rosi Braidotti, İnsan Sonrası adını verdiği çaşışmasında, Rönensans'tan itibaren başlayan bir hümanist kusursuzlaşma idealinin Aydınlanma'yla birlikte nasıl bir akıl, ilerleme ve gelişme saplantısına dönüştüğünü, bu tablonun da hızla nasıl "erkekinsan"ın kurtuluş anlatısına el verdiğini ve hepsinin sonunda ortaya çıkan tarihsel bir hümanizm düşüşünün nasıl bir hayal kırıklığı yarattığını ayrıntılarıyla örnekler (Bkz. Braidotti 2013: 23-62).
} 
olmaktan öteye geçemeyecek bir muğlaklık olduğunu söyledi. Nesnel gerçeklik hakkında düşünmek, onu aramak, bulmaya çabalamak ya da onu azar azar daha az yanılgılı kavramaya çalışmak gibi tutumlar felsefede hepten gözden düştü, bilimde de totaliter bir aydınlanmacılık heveslisi olmakla bir sayıldı (Kuhn, Rorty, II. Dönem Wittgenstein, Derrida, Levinas bu koronun temel sesleri arasında sayılabilir).

Böylece, felsefe -klişe bir ifadeye başvurursak- içindeki çocuğu öldürdü; içindeki doğa filozofunu öldürdü; ontolojiyi terk etti; olumsuzlamadan ibaret bir epistemolojiyi aldı ve tüm dikkatini büyük harfli bir bilim ve aydınlanma değillemesine odakladı... Kuşkusuz, Spinozacı bir perspektiften bakılırsa, her şey olması gerektiği gibi olur ve öyle de olmuştur. Felsefenin bu kendi evriminden öğreneceğimiz dersler de yok değildir. Ne var ki, gerçekliği bilme tutkusunun totaliter bir kibre dönüşmesine izin vermeme etiği, ontolojiyi hepten terk etme gibi bir sonuca varınca, bu kez felsefeye karşı bir şiddet uygulamaya dönüştü. Son derece etik görünümlü bir şiddet! Belki de son kırk yıldır felsefenin mağdur ve mazlum tek “öteki”si var, o da ontoloji.

Bugünlerde kendilerini “yeni realizm”, “yeni materyalizm”, “eleştirel realizm” ya da "spekülatif realizm" gibi adlar altında toplayan bir düzine kadar filozof üstte yazılanları genel olarak paylaşıyor (Maurizio Ferraris, Manuel de Landa, Roy Bhaskar, Bruno Latour, Graham Harman, Levi Bryant vb.). Bu düşünürler, gerçekliği terk etmeye niyetleri olmadığını söylüyorlar. Dahası, gerçekliği arama çabasının terk edilebilir olmadığını, gerçekliğin kimi unsurlarının (social objects) dil içinde ve dil dolayımıyla kurulmakla birlikte, tüm gerçekliğin dilsel bir temsilden ibaret sayılamayacağını, felsefenin de hakikat arayışından uzak durması gereken bir dil oyununa dönüşmemesi gerektiğini ileri sürüyorlar. Bu düşünürlerin her birinin şu ya da bu ölçüde birbirinden farklı ontoloji denemesi var; çünkü, üstte anlatılanlardan çıkarılacağı üzere, hiçbiri ontolojiyi epistemolojiye indirgemekten yana değil. Gerçeklik yanılmaz, bizim bilme çabamız yanılgılarla doludur... Öyleyse, bilme çabamızın yanılabilirliğini akıldan çıkarmadan, bilme çabasının daha az yanılgılı arayışlarını sürdürmek gereklidir. 


\section{Nesne Merkezli Ontoloji (Object Oriented Ontology) Arayışı}

Kantçı epistemolojiye karşı farklı terimlerle sürdürülen yeni gerçekçi itirazın ortak kullanımındaki kavram ilk kez Fransız düşünür Quentin Meillasoux'un çokça tartışılan After Finititude (2008) adlı kitabından doğmuştur. Meillasoux, bu kitapta, "korelasyonizm (correlationism)" diye adlandırdığı bir epistemolojik tutumu Kant ve Kant sonrası felsefenin epistemolojik yaklaşımını eleştirmek için analiz eder. ${ }^{2}$ Meillasoux’a göre korelasyonizm insanın ancak düşünce ve varlık arasındaki korelasyona erişiminin olabileceği, ama bu iki kavramın herhangi birine birbirinden bağımsız erişemeyeceği kabulüdür. Düşünce ve varlık arasındaki korelasyon, böylece, hem düşünce hem de varlığın kendisini insanca bir soruşturmanın dışında bırakarak, insana yalnızca korelatif bir dolayım olanağı tanımaktadır. Aynı biçimde, Meillasoux'a göre, korelasyonizm fikri, varlığın (ya da Varlık'ın) zorunlu olarak sözü edilen korelatif dolayıma bağlı kılınması, ondan ibaret sayılması ya da ona indirgenmesi anlamlarına da gelmektedir.

Meillasoux'un korelasyonizm kavramıyla saptadığı tutumun Kant epistemolojisinin zorunlu bir implikasyonu olduğu konusunda yeni gerçekçiliğin tüm taraflarında ortak bir kabul vardır. Meşhur dogmatik uykusundan uyandırılışının ardından Kant haklı olarak kendinden önceki yüzyılda tüm belirtileri hem rasyonalist okulda hem de deneyci okulda ortaya çıkan kuşkuculuğa düşmekten kaçınmış, bir bakıma hem Kartezyen hem de Berkeleyci aşırılığın sağduyuya ters kuşkusundan uzak “temkinli bir gerçekçilik” peşine düşmüştü. Öte yandan, bu temkinli gerçekçilik Kant'1 "nümenal” dünyayı "fenomenal” dünyadan ayırmaya götürmekle kalmamış, insanın ilkine ilişkin bilgisinin olanaklı olmayacağını, dolayısıyla bilginin ancak ikincisiyle sınırlı kalacağını kabul etmeye de götürmüştür. ${ }^{3}$ Kant, deneyimlenen dünyanın ve bu

\footnotetext{
${ }^{2}$ Meillasoux'un sözü edilen kitabındaki analizlerin sonunda onu götürdüğü bir tür nihilizmin ayrıntılı eleştirisi Peter Halward tarafından yapılmıştır (Bkz. Halward 2011). Biz bu çalışmada Meillasoux'un yalnızca 'korelasyonizm' kavramı ve bu kavramın dayandığı argümana odaklanmayı seçtik.

${ }^{3}$ Shaviro Kant'ın bu yönelişini şöyle ifade eder: “(...) Kant, bir yandan dogmatizm ve kuşkuculuğun tehlikelerini kontrol altına alırken, diğer yandan da rasyonalizm ve empirismin taleplerini birleştirecek bir yapı geliştirmişti. Ve korelasyonizm Kant'ın bu yapıyı olanaklı kılmak amacıyla kendi rızasıyla ödediği bir bedeldi." (2014: 69).
} 
dünyadaki nesnelerin gerçekliğini kabul eder görünmekle birlikte, bu nesnelere ilişkin bilginin nesnel gerçekliği (öznelerin ortak dilini aşan bir nesnel gerçeklik) konusundaki soruşturmanın zorunlu sonuçsuzluğunu göstererek bir anlamda nesnel gerçekliğin ve bu gerçekliğin nesnelerinin insani bir korelasyona hapsedilmesine yol açmıştır. ${ }^{4}$

Kantçı felsefe bu olguyu kabul etmekle birlikte bunun "kaçınılmaz” olduğunu ve Kant'ın bir anlamda malumu ilan ettiğini düşünür. Öte yandan, yeni gerçekçi düşünürlere göre Kantçı "nümenal” ile "fenomenal” ayrımı geçerli olsa bile, bu ayrımdan bilgiye çizilen Kantçı sınırlamanın (insan bağımlı bir sınırlama) çıkarılması geçerli değildir.

Meillasoux'a göre kendisinin "soyatasal (ancestral)” dediği türden önermeler karşısında takınmamız gereken tutum Kantçı bu bilinemezlik savını büyük ölçüde zayıflatmaktadır. Soyatasal önermeler, düşünüre göre evren hakkında dünyadaki biyolojik yaşamdan bile önce, dolayısıyla bilinçten çok önce bir gerçekliğin -bir anlamda- zorunlu kabulünü gerektiren verilere dayanmaktadır. Meillasoux bunu şu soruyla gündeme getirir: "Korelasyonizm soyatasal önermeleri yorumlama açısından nasıl bir yükümlülüğü vardır?” Bu tür önermelerden bir tanesi şudur: "Evren, 13,5 milyar yıl önce oluşmuştur." Sorunun Kantçı epistemolojiye yönelik meydan okuması ilk göründüğünden daha ciddidir. Kantçı bir korelasyonist bu önermenin doğruluk değerini nasıl belirleyebilir? Evrenin 13,5 milyar yıl önce oluştuğu önermesinin doğruluk değeri insana göre mi, yoksa nesnel gerçekliğe göre mi belirlenecektir? Meillasoux, bir korelasyonist için bu önermenin doğruluk değerinin ancak "insana göre" bir koşulla belirlenebilir olduğunu; ne var ki, öyle bir durumda önermenin nesnel gerçeklik hakkındaki bilgi vericiliğinin ortadan kalkmış olacağını söyler. Kendi-içindeşey olarak evren 13,5 milyar yaşında mıdır, yoksa insanın a priori bir dolayımla evrene biçitiği bir yaş mıdır bu?

Meillasoux'un bir anlamda korelasyonist bir özneler-arasıcılık döngüsünden bağımsız, orada ve insan zihninden ontolojik anlamda bağımsız bir nesnel gerçekliğin

\footnotetext{
${ }^{4}$ Kant'ın, fenomenal alandaki koşullu bilgimizin yegane olanağı olarak "şeyler"in gerçekliğine ilişkin kabulüyle ilgili olarak, bkz. Kant 1929: 27.
} 
olduğuna ilişkin dikkate alınması gereken önermelerden diğer bir grup da kendisinin "fosil maddeler" dediği türden önermelerdir. Meillasoux bu türden önermeler için şunları ileri sürer:

Arke-fosil ya da fosil madde diye adlandıracağım materyallerin, fosil teriminden
aşina olduğumuz üzere, yalnızca geçmiş bir yaşamın izleri olduğunu değil, aynı
zamanda soyatasal bir gerçeklik ya da olayın varlığını ifade eden materyaller
olduğunu ileri süreceğim. Bir arke-fosil bu anlamda soyatasal bir fenomenin
ölçümüne ilişkin deneylere olanak veren maddi bir dayanak anlamına gelir -
örneğin, radyoaktif bozunum değerini bildiğimiz bir izotop, ya da bir yıldızın
oluşum tarihine ilişkin bize bilgi veren 1şı emilimi gibi (Meillasoux 2008: 10).

Meillasoux, soyatasal önermeler ya da fosil-madde olgularına ilişkin önermelerin Kartezyen bir bilim anlayışında sorun çıkarmazken Kantçı bir korelasyonistin bilim anlayışı için ciddi bir sorun anlamına geldiğini ileri sürer. Mesela açıktır: $\mathrm{Bu}$ türden önermelerin ancak mecazi bir anlamı olduğu ileri sürülmeyecekse, korelasyonist için bilimi insan merkezli ve öznelere arası bir faaliyet saymaktan kurtaracak başka ne yol vardır? Şu örnek ilginçtir:

Şu soyatasal önermeyi düşünelim: 'İnsanlar ortaya çıkmazdan X yıl kadar önce Y olayı gerçekleşmiştir.' Korelasyonist bir filozof herhangi bir biçimde önermenin içeriğiyle uğraşmayacaktır: Onun işi gerçekte ne $\mathrm{Y}$ olayının gerçekleşip gerçekleşmediği ne de bu olayın tarihiyle ilgili bir itirazdır. Hayır, o yalnızca şunu ekleyecektir- ifadenin sonuna, belki yalnızca kendine hitaben, ama önermeye kesin bir ek olarak, basit bir düzeltme olarak, her zaman aynı düzeltme olacak biçimde: 'İnsanlar ortaya çıkmazdan X y1l kadar önce Y olay1 gerçekleşmiştir -insana göre (hatta, bilim insanına göre) (Meillasoux 2008: 15).

Kant epistemolojisinde Meillasoux'un dillendirdiği bu tutum, spekülatif gerçekçilik olarak nitelendirilen perspektife göre objeler dünyasının inkar edilmesine kadar varan bir ilgisizliği peşinden getirmiş, insan merkezli bir gerçeklik kavrayışını kendi kendine çizdiği sınırlar içinde- ya objelerin nesnel dünyasından koparmış ya da bu dünyayı insancı bir korelasyonizme indirgemiş, adeta objelerin nesnel var olma tarzlarını asimile etmiştir. Graham Harman tarafından geliştirilen ve yine spekülatif realizm perspektifi içinde kendine özgü bir obje merkezli ontoloji (OMO) [İngilizce: Object Oriented Ontology (OOO)] arayışını ifade eden program da Kant'ın Meillasouxcu eleştirilerinden haberdar ve bunları aşan bir gerçekçilik örneği olarak 
belirmiştir. Harman, Peter Gratton'a göre, özellikle Tool Being: Heidegger and the Metaphysics of Objects (2002) ile Quadruple Object (2011) arasında yaklaş1k on y1lda biçimlendirdiği programda, bir taraftan Husserlci 'objeler ve nitelikler' ayrımından yararlanarak ikincisinin ilki tarafından tüketilemeyeceğini gösterme yoluna gitmiş, diğer taraftan da Heideggerci ontolojiden yararlanarak gerçekliğin şeyler düzeyinde her zaman bir tür bilincin erişimine kendini açma ve geri çekme süreci olacağı saptamasını geliştirmeyi amaçlamıştır (Gratton 2014: 87). Bu iki kaynaktan, önce beslenişi, sonra da onları aşma çabası Harman'ın Quadruple Object adlı kitabındaki şu ifadede netlik kazanır: "Bizim bir zemini 'ayakta durmaya yarayan gereç' olarak kullanışımız, köpeklerin ya da sivrisineklerin ayırt edebileceği niteliklerin bolluğuna yönelik herhangi bir teması olanaklı kılmaz. Kısacası hem teori hem de pratik, şeyleri kendini-açmayahazır bulunuşluğa (presence-at-hand) indirmekten ötürü eşit oranda suçludur.” (Harman 2011b: 38).

Harman'ın geliştirmek istediği Obje Merkezli Ontoloji, Kant epistemolojisinin fenomenal/nümenal ayrımını kabul eder görünmekle birlikte, Meillasoux'un itirazlarını dikkate alacak biçimde, fenomenal alanın insan-bilinci-merkezli bir korelasyonizme terk edilmesinin önüne geçmek ister. Bir başka deyişle, Harman için de, Kant'tan tümüyle farklı gerekçelerle de olsa, şeylerin-kendi-içlerinde oluşlarından mamül bir gerçeklik vardır ve bu gerçeklik her zaman insan bilincinin kuşatabileceğinden fazla ve çeşitli etkileşimler dünyası olarak tezahür edecektir. Ne var ki, fenomenal alan Kant'ın yaptığı gibi insan-bilinci-merkezli bir korelasyonizme terk edilmeyecek, bu alan objelerin insanlarla olduğu kadar insan-dışı, hatta canlı-dışı tüm objelerle karşılaşmalarının ortak alanı olarak araştırma konusu edilecektir. Harman, The Speculative Turn'de objeden ne anladığını yazarken bu arayışın izleri belli olur: ““Objeler' derken, bizden ve diğer şeylerden (birbirlerinden de) özerk belli niteliklere sahip bütünleşik entiteleri anlıyorum.” (Harman 2011a: 22). Bu hamleyle Harman, Meillasoux'un dikkat çektiği türden soyatasal önermelerin işaret ediyor olabileceği türden bir nesnel gerçeklik konusundaki kuşkulu tutumu ortadan kaldırmayı, aynı zamanda da objeleri insan-bilinci-merkezli bir korelasyonizmden kurtarmayı hedefler. 
Harman'ın özellikle son dönem düşüncesinde objelere yukarıda sözü edilen türde bir özerklik kazandırmak üzere "duyumsal” olanla "gerçek" olan arasında bir ayrımına gittiği görülür. Bir indirgemeyi göze alarak söylenirse, duyumsal obje insan zihninin bir objeyle etkileşme sırasında/sürecinde yarattığı (yaratabileceği) temsilin tamamı anlamına gelir. Kuşkusuz, Harman burada iki tür obje vardır demez; onun vurgusu gerçek bir objeyle insan zihninin karş1laşmasında zorunlu olarak bir duyumsal obje temsilinin olacağını göstermeye yöneliktir. Burada ona göre kaçınılması gereken objenin duyumsal olandan ibaret bir temsile hapsedilmesidir; çünkü duyumsal olan gerçek objenin bu 'spesifik' karşılaşmada (ve bütün başka tekil spesifik karşılaşmalarında) ilişkiye açtığı niteliklerle olanaklı olur, ama gerçek objenin bütün karşılaşmalarda (insan zihni ya da diğer objelerle) geriye çekip sakladığı nitelikler hep olacak, bu anlamda gerçek obje karşılaşmalarda asla tüketilmeyecektir (Bkz. Harman 2011a).

Harman bu vurgusuyla, Heidegger'den aldığı yardımla yeni bir düşünceyi ayağa kaldırmak, ama hemen ardından Heideggerci desteği terk ederek gerçek objenin bütün tekil-spesifik karşılaşma deneyimlerinde hep kendinde eksilmeden kalacak bir nitelik rezervini güvence altına almak ister. Harman'a göre "gerçek obje” Kantçı anlamda bir nümenal alanın yerleşik sakini değil, tümüyle fenomenal alanda ama nümenal konfordan da sonsuzca yararlanma olanağına sahip bir gerçekliktir.

Harman'ın Quadruple Object adlı çalışması, yukarıda açıklananlar 1şı̆̆ında değerlendirildiğinde, objeye bütün insani ve insani olmayan koşullardan bağımsız bir mutlak özerklik tanıma yolunda Batı metafiziğiyle hesaplaşma olarak okunabilir. Düşünüre göre, Batı felsefesinin "obje” açısından genel bir değerlendirmesinin açıkça gösterdiği şey objeye yönelik iki yanlış perspektifte 1srardır. Bu 1srardan biri objeyi “değersizleştirme (undermining)" ise diğeri de objeyi "aşırı yüceltme”dir (overmining). Harman'a göre ilk türden 1srarın mimarları arasında çağdaş felsefede Manuel de Landa gibi yeni materyalistlerden antik felsefenin atomcularına kadar uzanan köklü bir materyalist doğalcı yanılgı vardır. Bu yanılgı Harman'a göre kendisini objeyi sürekli olarak onu oluşturan temel yapıtaşları ile birlikte düşünüp, en alttaki, en somut, en 
bölünemez ya da en temel olanı obje karşısında daha gerçekçi bir statüye yükseltmek ister. Bu perspektifin gözünde, sözgelimi, bir ağaç -bir ağaç olarak mevcut durumundan ziyade- kendisini oluşturan karbon molekkülerine, o molekülleri kuran atomlara ya da daha alt parçacıklara indirgenmek suretiyle adeta gerçekliğini kazanır.

Öte yandan, objeyi aşırı yüceltme biçiminde ortaya çıkan diğer 1srar eğiliminde obje yine olduğu gibi olarak değil, bu kez de kendisine kurucu yapıtaşlarından biri rolü verilmek suretiyle insan zihninin eseri sayılabilecek makro-sosyal gerçekliğin oluşumunda abartılmış bir ilişkisellik örüntüsü altında ele alınırlar. Harman'a göre objeyi bu türden bir makro ilişkiselliğin unsuruna dönüştürerek onu bu kez de aşırı etkinleşmeye mahkum eden ısrarın sorumluları arasında Whiteheadci düşünce ve izleyenleri vardır." Harman bu iki ayrı yanlış tutum için şunları yazar: "Bireysel objelelerin metafiziğin kendi başına merkezi bir konusu olmasına direnenler için başka bir seçenek yoktur: Obje ya aşağıdan değersizleştirilecek ya da yukarıdan aşırı değerli kılınacaktır. Obje ya derinlerde yatan bazı ilksel elementlere indirgenecek, ya da yanılgılı bir biçimde doğrudan verilenle yer değiştirilerek gizemli bir takviye olarak resmedilecektir." (Harman 2011a: 13).

\section{Yoldaki Güçlükler}

Peter Heft, kitabında Graham Harman'ı anlatacağı bölüme başlarken düşünürün Kant'la ilişkisini özetleyen şu paragrafa yer verir: "Eğer Kant, (...) felsefenin jokeriyse Graham Harman da felsefenin Batman'idir. Kant dünyayı insan düşüncesiyle ilişkisine indirgemeyi isterken, Harman insan düşüncesinden tümüyle bağımsız obje-obje etkileşiminin kurduğu bir dünya imgelemek ister, Kant aşkınsal idealizmi kucaklamak isterken Harman realizmi metafizik açıdan güvenilir bir pozisyona dönüştürmek ister, ve Kant nümenal'in bilinemez olduğunu söylerken Harman nümenali Gerçek kılmak ister." (Heft 2016: 24).

Buraya kadar anlatılanlar 1şı̆̆ında, Harmancı gerçekçiliğin temkinli bir eleştirisini yapmak için belli koşulların oluştuğunu ileri sürebiliriz. Bu eleştiri temkinli

\footnotetext{
${ }^{5}$ Harman'a göre Bruno Latour da bu tutumun temsilcileri arasındadır.
} 
olmalıdır çünkü, bir yandan Harman'ın (Meillasoux ile uyumlu olarak) dikkat çektiği Kantçı epistemolojinin olumsuz sonuçlarına ilişkin dikkat çektiği noktalar haklı bulunabilir türdendir, ama öte yandan Kantçı epistemolojinin olumsuz sonuçlarını eleştirmenin "sonuçlara öykünmek (appeal to consequences)" türünden bir biçimsel olmayan mantık hatasına düşmesinin kabul edilemeyeceğini de fark etmek gerekecektir. Kantçı epistemolojinin tüm gerçekliği insan merkezli bir aşkınsal idealizmin kavramlarına hapsettiğini tespit etmek ayrı, bu epistemolojinin yanlış olduğunu göstermek ise apayrı birer temelledirme güçlügü olarak durmaktadır. Harman'ın fenomenal dünyaya ilişkin spekülatif betimlemelerinin bilimsel önermelerin nesnel gerçekliğini geri kazanmak için önemli bir çaba olduğunu kabul etmekle, bu geri kazanımın nasıl olanaklı olacağına ilişkin temellendirmenin henüz yapılamadığını söylemek eşit ölçüde geçerli iki farklı yargıda bulunmak anlamına gelir. Çünkü ikincisi Kantçı aşkınsal kategorilerin yetkin bir eleştirisini gerektirir ki bunun henüz gerçekleşmediği açıktır. Harman'ın imgelediği türden bir fenomenal dünyada objelerin objelerle ilişkisini düşünürken Kant'ın aşkınsal kavramlarından muaf bir dilin geliştirilmesi olanaklı mıdır? Eğer bu olanaklı değilse, obje-merkezli bir ontolojinin epistemoloji içinde eritilmesine karşı gerçekçi itirazın temellendirilmesi nasıl yapılabilir?

Spekülatif gerçekçiliği Whiteheadci bir süreç ontolojisi üzerinden izleyen Shaviro'ya göre projenin başarısı büyük ölçüde yukarıda sözü edilen türde yetkin bir Kant eleştirisinin yapılabilmesine bağlıdır. Shaviro henüz elde olanın "negatif bir tez" olduğunu, gerçekçi bir metafiğin aynı zamanda Kant’tan bağımsılaşmayı başarabilmiş “pozitif bir tez”e gereksinim duyduğunu ileri sürer. Shaviro, Meillasoux 'la başlayan bu araştırma programının temel misyonu için -Marx’1 anımsatacak bir ironiyle- şöyle yazar: "Filozoflar bu güne dek çeşitli biçimlerde yalnızca korelasyonist döngüyü tanımladılar, asıl sorun bu döngüden dışarı çıkabilmektir.” (Shaviro 2014: 68). 
Shaviro'ya göre, Kantçı bilinemezlik ya da kendisinin deyimiyle “... (Kant'ın çizdiği sınırlardan) ${ }^{6}$ geriye kalanla yetinecek bir gerçekçiliğin çağdaş felsefede yarattığı hayal kırıklığı”, ancak negatif bir tutumla korelasyonizm eleştirisiyle yetinmekten vazgeçip, pozitif bir ontoloji ve yine pozitif bir epistemoloji önermeyi gerektirmektedir (2014: 68). Shaviro burada sözünü ettiği pozitif ontolojik tezin, şeyleri yalnızca insan kavramsallaştırmalarından bağımsız varoluşlarıyla değil, şeylerin kendi-içlerinde nasıl organize oldukları ve onları olanaklı kılan etkileşimsel koşulların nasıl bir süreç izlediğine ilişkin de insancı şemalardan kurtulmayı başarmış bir dile gereksinim duyacağını yazar. Harmancı tez önerisi, Shaviro'ya göre bu bağlamda olumlu bir çabadır ve aslında Kant'ı tümüyle bir tarafa atmak yerine -tam tersine- Kantçı nümenal bilinemezliği insanın kendinde şeylere erişimine ilişkin bir olanaksızlıktan ziyade, insan da dahil her bir obje için (şey’in şeylerle ilişkisi) her zaman hakkında konuşulan şey'de konuşmanın tüketemeyeceği (karşılaşmaların tüketemeyeceği demek daha doğru) bir yanın kalacağını kabul etmeye doğru bir genişletme anlamına gelir (2014: 70). Böylece, Shaviro'nun vurguladığı gibi, objelerin insan zihninden bağımzılığını ilan etmenin Harmancı anlamı, objelerin gerçek objeler olarak değil her zaman duyumsal objeler olarak düşünülmesi, ancak bunun salt insana ait bir olanaksızlık olmaktan çok objenin objeyle ilişkisini de bağlayan gerçekliğin nesnel bir ifadesi olarak düşünülmesi amaçlanmaktadır.

Ferraris, Yeni Realizm için Manifesto'nun (Manifesto for New Realism) ilk sayfalarını Kant'ın planlanmamış etkisinin postmodernizme nasıl dönüştüğünü, benzer biçimde postmodernizmin planlanmamış bir etkisi olarak da günümüz felsefi, etik ve politik dinamiklerini doğrudan belirleyen yıkıcı bir popülizme nasıl evrildiğini açıklamaya ayırır (Bkz. Ferraris 2012). Dolayısıyla, bugün deneyimlediğimiz ve felsefeden siyasete, etikten gündelik yaşama kadar belirleyici olan, bir anlamda, 'her şey mübah' tutumunun öngörülmedik dolayımlardan geçerek Kant sonrası tüm yaşamı kuşattığı söylenebilir. Ferraris bu tablonun yakın ve kasıtlı nedeninin postmodernizm olduğunu düşünmez; daha çok postmodernizmin sağladığı iklimde kendine sağlam bir

\footnotetext{
${ }^{6}$ Parantezli ifade bana aittir (ÇB).
} 
ideolojik dayanak bulan popülizmdir sorumlu olan. Broidotti’nin 'insan sonrası' olarak adlandırdığı bu dönem kendini içinde bulduğu çok yönlü yıkıcılıktan kurtarmak için gerçeklikle ilgili yeni bir tavra gereksinim duymaktadır. Ferraris için bu çaba, bir anlamda, totaliter hırsından arınmış alçakgönüllü yeni bir aydınlanma olarak okunabilir: “Aydınlanma, bugün, hala bir dayanak ve insanlığa imana gereksinim duymaktadır; ama bu insanlık kurtarılmayı bekleyen düşmüş bir tür olarak değil de evrilmekte olan ve yolda akılla donanan bir hayvan türü olarak alımlanacaktır.” (2012: 21). 


\section{KAYNAKÇA} Kitap.

BRAIDOTTI, R. (2013). İnsan Sonrası, çev. Öznur Karakaş, İstanbul: Kolektif

FERRARIS, M. (2012). Manifesto of New Realism, trans. by Sarah De Sanctis, New York: Sunny Press.

GRATTON, P. (2014). Speculative Realism, London: Bloomsbury Publishing.

HALLWARD, P. (2011). "Anything is Possible: A Reading of Quentin Meillassoux's After Finititude", The Speculative Turn, ed. by Levi Bryant, Nick Srnicek \& Graham Harman, Melbourne: re.press series.

HARMAN, G. (2011a). "On the Undermining of Objects: Grant, Bruno, and Radical Philosophy", The Speculative Turn, ed. by Levi Bryant, Nick Srnicek \& Graham Harman, Melbourne: re.press series. Books.

HARMAN, G. (2011b). The Quadruple Object, Winchester, England: Zero

HEFT, P. (2016). “The Philosopher's New Clothes: An Introductory Survey into Object-Oriented Ontology", Yayınlanmamış Denison University Yaz Okulu Projesi Notlar1, Erişim Tarihi: 20.06.2017 (http://www.petersaysstuff.com/wpcontent/uploads/2016/08/The-Philosophers-New-Clothes-An-Introductory-Survey-intoObject-Oriented-Ontology.pdf).

KANT, I. (1929). Critique of Pure Reason, trans. by N. K. Smith, London: Macmillan.

MEILlASSOUX, Q. (2008). After Finititude: An Essay on the Necessity of Contingency, trans. by Ray Brassier, London: Continuum.

SHAVIRO, S. (2014). The Universe of Things: On Speculative Realism, London: University of Minnesota Press. 